\title{
Early life characteristics, social mobility during childhood and risk of stroke in later life: findings from a Swedish cohort
}

Amy Heshmati ${ }^{1}$, M. Pia Chaparro ${ }^{1,2}$, Anna Goodman $^{1,3}$, Ilona Koupil ${ }^{1,4}$

1 Centre for Health Equity Studies (CHESS), Stockholm University/Karolinska Institutet, Stockholm, Sweden

2 Department of Global Community Health and Behavioral Sciences, School of Public Health and Tropical Medicine, Tulane University, New Orleans, USA

3 London School of Hygiene \& Tropical Medicine, London, UK

4 Department of Public Health Sciences, Karolinska Institutet, Stockholm, Sweden

Corresponding author: Amy Heshmati, Centre for Health Equity Studies (CHESS), Stockholm University/Karolinska Institutet, Sveavägen 160, Floor 5, 10691 Stockholm, Sweden (amy.heshmati@chess.su.se)

Note: this is a personal version, created by Anna Goodman, of the text of the accepted journal article. It reflects all changes made in the peer review process, but does not incorporate any minor modifications made at the proof stage. The complete citation for the final journal article is:

- Heshmati, A., Chaparro, P., Goodman, A. \& Koupil, I. 2017. Early life characteristics, social mobility during childhood and risk of stroke in later life: findings from a Swedish cohort. Scandinavian Journal of Public Health, 45, 419427.

- DOI: $10.1177 / 1403494817696600$

Copyright (C) and Moral Rights for this paper are retained by the individual authors and/or other copyright owners 


\begin{abstract}
$\underline{\text { Abstract }}$
Aims: To investigate if early life characteristics and social mobility during childhood are associated with incident thrombotic stroke (TS), haemorrhagic stroke (HS) and other stroke (OS).

Methods: Our study population consists of all live births at Uppsala University Hospital in 1915-1929 (Uppsala Birth Cohort; $n=14,192$ ), of whom 5,532 males and 5,061 females were singleton births and lived in Sweden in 1964. We followed them from 1 January 1964 until first diagnosis of stroke (in the National Patient Register or Causes of Death Register), emigration, death, or until 31 December 2008.Data were analysed using Cox regression, stratifying by gender.
\end{abstract}

Results: Gestational age was negatively associated with TS and OS in women only. Women had increased risk of TS if they were born early preterm ( $<35$ weeks) (HR 1.54 (95\% CI 1.02-2.31)) or preterm (35-36 weeks) (HR 1.37 (95\%CI 1.03-1.83)) compared to women born at term. By contrast, only women who were early preterm (HR 1.98 (95\%CI 1.27-3.10) had an increased risk of OS. Men who were born post-term $(\geq 42$ weeks) had increased risk of HS (HR 1.45 (95\%CI 1.04-2.01)) compared with men born at term, with no association for women. TS was associated with social mobility during childhood in women: women whose families were upwardly or downwardly mobile had increased risk of TS compared to women who were always advantaged during childhood.

Conclusion: Gestational age and social mobility during childhood were associated with increased risk of stroke later in life, particularly among women, but there was some heterogeneity between stroke subtypes.

Key Words: childhood, birth outcomes, gestational age, preterm birth, social mobility, stroke 


\section{$\underline{\text { Introduction }}$}

Low birthweight and reduced foetal growth are associated with increased risk of cardiovascular disease (CVD) in adulthood; [1-4] however the link with gestational age is less evident. Although infants born prematurely ( $<37$ weeks gestation) have increased rates for CVD risk factors, such as high blood pressure,[5] type-2 diabetes,[6, 7] and increased adiposity,[8] the relationship between preterm birth and CVD remains unclear.

Previous studies from the Uppsala Birth Cohort Multigenerational Study (UBCoS Multigen) have found an association between gestational age and stroke; $[9,10]$ specifically, a negative linear trend between gestational age and stroke mortality,[9] and an association between gestational age and incident 'other' (undefined) stroke among women in a sub-sample.[10] Similarly, a cohort study based on the total population of Sweden found those born very early preterm $(<32$ weeks) had increased risk of stroke in young adulthood.[11] However, research[12, 13] from the Helsinki Birth Cohort Study has found no association between preterm birth and incident stroke.

Birthweight,[13-15] birthweight-for-gestational-age,[9, 10] birth length,[13, 14] head circumference[13] and placental weight, $[13,14]$ have also been investigated in relation to stroke risk in adulthood, with only birthweight and birthweight-for-gestational-age consistently showing a negative relationship.

Furthermore, CVD and its risk factors follow an inverse social gradient: individuals who have adverse socioeconomic conditions during childhood have increased risk of CVD in later life.[16] Although little is known about the effect of social mobility during childhood and its effect on stroke in adulthood, it could be hypothesised that individuals with accumulated disadvantage will have poorer health outcomes in adulthood.

There are two types of stroke: thrombotic (or ischaemic) stroke (TS) and haemorrhagic stroke (HS), with TS accounting for approximately $87 \%$ of all strokes.[17] TS and HS have differing pathophysiology, yet most studies group them together. Ascertaining specific determinants of different types of stroke may provide important insights for stroke prevention.

Using data from UBCoS Multigen Study, our aim was to investigate the associations between early life characteristics and incident TS, HS and 'other' (undefined; OS) stroke. We extend previous studies $[9,10]$ by including an additional follow-up of seven years,[9] by focussing on incident strokes (rather than mortality) and their subtypes,[9] by expanding on a previous analysis which only looked at a smaller subsample of women for whom pelvic size measurements were available; [10] and most importantly, by examining the combined effect of gestational age and social mobility during childhood on incident stroke. 


\section{Methods}

Data comes from the first generation of UBCoS Multigen (http://www.chess.su.se/ubcosmg/), including all 14,192 live births born at Uppsala University Hospital, Sweden in 1915-1929.[18, 19] Parish records were used to trace the cohort members' emigrations and deaths until register data became available in the 1960s; these records had $\sim 98 \%$ completeness to follow-up. We restricted our sample to singleton births $(n=13,748)$ and those still alive and resident in Sweden in 1964 $(n=11,580)$. Our final sample comprised of 10,593 individuals who had complete data on social and health characteristics at birth. Additional analyses on social mobility during childhood had a study population of 7,985 individuals. The study was approved by the Regional Ethics Committee in Stockholm.

\section{Variables}

Data on birth characteristics were derived from obstetric records. Our primary focus was gestational age measured by date of last menstrual period. Gestational age was categorised into four groups: early preterm ( $<35$ completed weeks of gestation), preterm (35-36 weeks), term (37-41 weeks), and post-term ( $\geq 42$ weeks). Other birth characteristics examined were birthweight-standardised-for-gestational-age (z-score), birth-length-standardised-for-gestational-age (z-score), and head-(occipito-frontal)circumference-standardised-for-gestational-age (z-score), all categorised into quartiles; placental weight categorised into four groups: $\leq 550 \mathrm{~g}, 551-650 \mathrm{~g}, 651-750 \mathrm{~g},>750 \mathrm{~g}$; and placental weight in relation to birthweight (percentage) categorised into four groups: $\leq 16.5,16.5-18.5,18.5-20.5,>20.5$. Gender-specific z-scores of birth-length-standardisedfor-gestational-age and head-circumference-standardised-for-gestational-age were created for this study and were calculated using the cohort as a reference, excluding individuals who were born $<30$ weeks gestation $(n=5)$. The category limits for the placental weight variables were based on limits used in a previous UBCoS Multigen study.[20]

Our social indicators were family social class at birth and social mobility during childhood. Family social class at birth was based on father's occupation or mother's occupation if she was single, and was obtained primarily from obstetric records (97.9\%), with $2.1 \%$ of the data coming from census 1930. Family social class at birth was categorised into five groups: higher and intermediate non-manual, entrepreneurs and famers, lower non-manual, skilled manual, and unskilled manual. Social mobility during childhood was created using family social class at birth and family social class at aged 10 , which was also based on father's occupation or mother's occupation if she was single (75.4\% with available data, drawn primarily from archived school records). Individuals were classified into two groups at each time period: advantaged, which included high and intermediate non-manual, entrepreneurs and farmers, lower non-manual and skilled manual social classes; and disadvantaged which were those from unskilled manual social classes. Accordingly, social mobility during childhood was categorised into four groups: always advantaged, upwardly mobile, downwardly mobile, and always disadvantaged. 
Included covariates were birth year (1915-1919, 1920-1924, and 1925-1929) to control for potential cohort effects, maternal age at birth (continuous), and parity (categorised into parity 1 , parity 2 and parity $3+$ ).

Incident TS, HS, and OS were defined as the first recorded hospitalisation or death with the respective diagnosis as the main or contributing diagnoses. Data was obtained from the National Patient Register (validity of 85-95\%)[21] and the Causes of Death Register. The following International Classification of Diseases (ICD) codes were used to define TS: ICD-7 (332-333); ICD-8 (432-435, 437); ICD-9 (433-435); and ICD-10 (G45, I63, I65, I66); HS: ICD-7 (330-331); ICD-8 (430-431); ICD-9 (430-432); and ICD-10 (I60I62); and OS: ICD-7 (334); ICD-8 (436,438), ICD-9 (436-438); and ICD-10 (I64, I67I69).

\section{Missing data}

The attrition analysis between our eligible sample $(n=11,580)$ and our main study population $(\mathrm{n}=10,593)$ showed that our excluded individuals were more likely to be born between 1915 and 1919 (44.7\% vs 24.3\%), from unskilled social classes at birth $(54.6 \%$ vs $49.5 \%$ ), to be born before 35 weeks gestation $(3.5 \%$ vs $1.8 \%)$, to have lower birthweight $(3,415 \mathrm{~g}$ vs $3,467 \mathrm{~g})$ and smaller head circumference $(34.7 \mathrm{~cm}$ vs $34.8 \mathrm{~cm})$. Comparisons with our population for the analyses on social mobility during childhood $(n=7,985)$ and the excluded individuals who lacked data on family social class at aged 10 $(\mathrm{n}=2,608)$ showed that excluded individuals were more likely to be born between 1925 and 1929 (47.2\% vs 39.1\%) and from higher and intermediate non-manual class $(11.1 \%$ vs $8.3 \%)$, entrepreneurs and farmers $(20.1 \%$ vs $18.8 \%)$ and unskilled manual $(51.3 \%$ vs $49.0 \%$ ) social classes at birth.

\section{Statistical Methods}

We used STATA v11 to perform descriptive statistics and fit Cox proportional hazards models. Follow-up began on 1/Jan/1964 when the Hospital Discharge Register was launched21 and continued until diagnosis with stroke, emigration, death, or until 31/Dec/2008. All analyses were stratified by gender, and were initially adjusted for birth cohort with individual's age defining the time scale. Analyses for gestational age were further adjusted for family characteristics at birth, birthweight-for-gestational-age and placental weight/birthweight ratio in a series of hierarchical models. Analyses for the other birth characteristics were only further adjusted for gestational age and birthweightfor-gestational-age.

We explored potential interactions with gestational age, gender, parity and family social class at birth. For the tests with family social class at birth, social class was categorised into three groups: high (higher and intermediate non-manual, and entrepreneurs and farmers), middle (lower non-manual and skilled manual) and low (unskilled manual) social class. 


\section{$\underline{\text { Results }}$}

Table 1 presents the characteristics of the sample; men at birth were heavier, longer, had greater head circumference, and a larger placental weight than women; however there was no difference between genders with regards to social characteristics. Social class at birth was associated with length of gestation $(\mathrm{p}=0.01)$; a higher proportion of individuals from unskilled manual social class were born early preterm $(2.1 \%)$ compared with those from high non-manual backgrounds (0.6\%) (Supplementary Table S1). There was no difference in the frequency of preterm birth according to birth year or birth cohorts. Rates of incident stroke are displayed in Supplementary Table S2. Rates for all stroke types were higher among men, with TS being the most prevalent in both men (536 cases per 100,000 person-years; 95\% CI 504-570) and women (464 cases; 95\%CI 434-496).

Table 2 displays the hazard ratios for stroke types by birth characteristics. Gestational age was negatively associated with TS and OS in women only. Women born prematurely ( $<37$ weeks) had increased risk of TS compared to women born at term. After further adjustment for parity, maternal age, family social class at birth, birthweight-forgestational-age and placental weight/birthweight ratio, these effects strengthened for both those born early preterm (HR 1.66 (95\%CI 1.10-2.50)) and preterm (HR 1.42 (95\%CI 1.06-1.90)). Only women who were early preterm ( $<35$ weeks) had an increased risk of OS and the effect was not changed significantly in hierarchical models (not shown). Gestational age was not associated with HS in women, but men who were born post-term had approximately 1.5 times the risk of HS compared with men born at term.

Tests for statistical interaction between gestational age and gender, gestational age and parity, and gestational age and social class at birth in their effects on stroke were nonsignificant.

Negative linear associations were observed between birthweight-for-gestational-age and TS in men $(\mathrm{p}=0.009)$, and OS in both genders $(\mathrm{p}<0.05)$. Placental weight and placental weight/birthweight ratio were associated with all stroke types, but to varying degrees. Placental weight was associated with TS in both men and women; however, in fully adjusted models the association only remained in women $(p=0.006)$. No association between placental weight and HS was observed in the minimally adjusted models, but there was a positive linear association in women after further adjustment with gestational age and birthweight-for-gestational-age $(\mathrm{p}=0.001)$.

Social class at birth was associated with HS in women only $(\mathrm{p}=0.049)$. OS was not significantly associated with social class at birth in either gender, although in women there was a suggestion of lower risk among the higher non-manual group compared to all other social classes (Table 2). TS was not associated with social class at birth, but was associated with social mobility during childhood in women $(\mathrm{p}=0.02)$ : women whose families were upwardly or downwardly mobile had increased risk of TS compared to women whose families were always advantaged during childhood. 
Table 1. Characteristics of study subjects born in Uppsala, Sweden, 1915-1929 stratified by gender (men n=5,532; women $\mathrm{n}=5,061$ ).

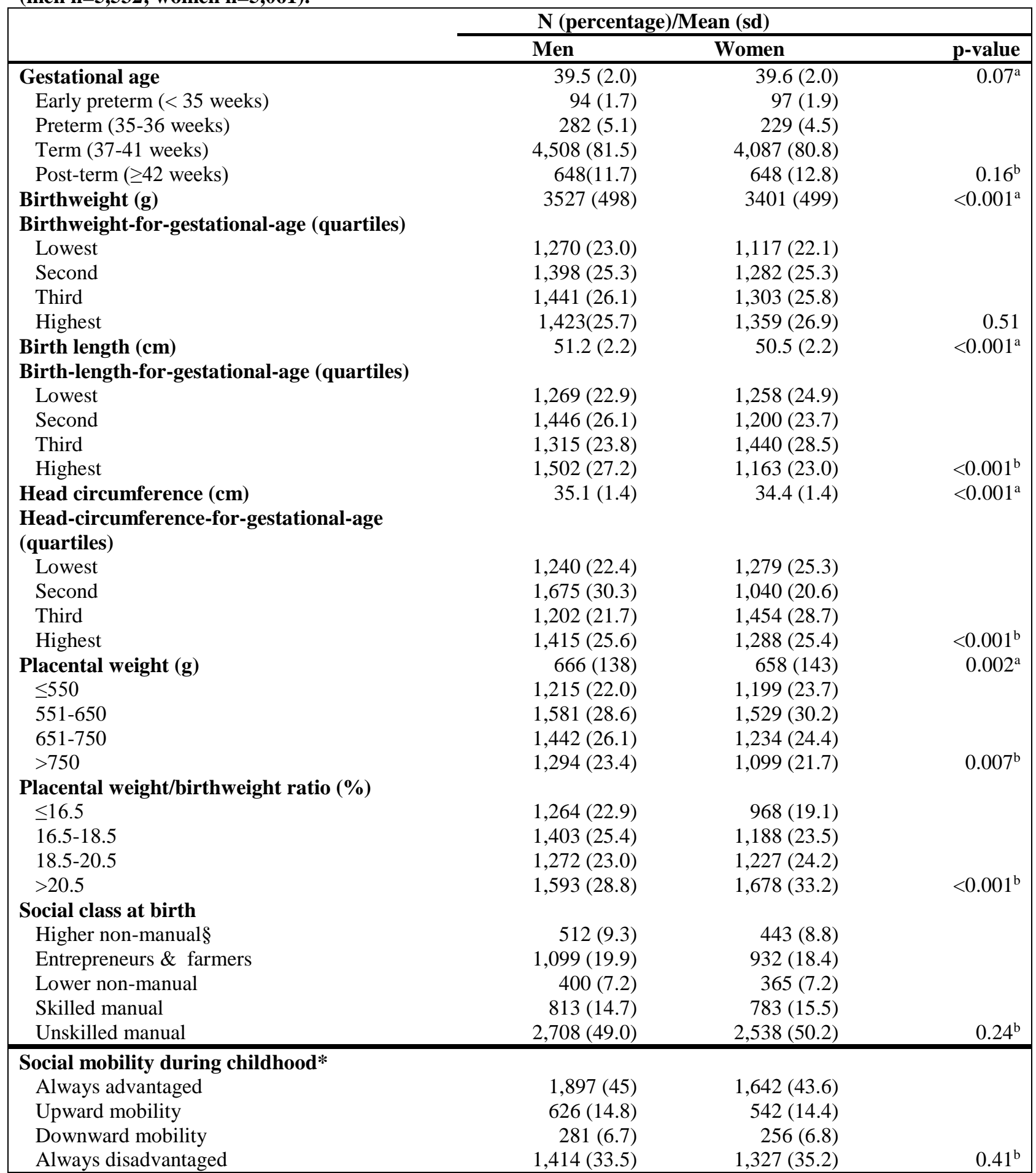

${ }^{\mathrm{a}}$ T-test. ${ }^{\mathrm{b}}$ Pearson $\chi^{2}$ test; $\S$ Includes intermediate non-manual social class

$* \mathrm{n}=7,985$ (men $\mathrm{n}=4,218$; women $\mathrm{n}=3,767)$ 



childhood stratified by gender ( men $n=4,218$; women $n=3,767$ ).

\begin{tabular}{|c|c|c|c|c|c|c|c|c|c|c|c|c|}
\hline & \multicolumn{4}{|c|}{ Thrombotic stroke } & \multicolumn{4}{|c|}{ Haemorrhagic stroke } & \multicolumn{4}{|c|}{ Other stroke } \\
\hline & \multicolumn{2}{|r|}{ Men } & \multicolumn{2}{|r|}{ Women } & \multicolumn{2}{|r|}{ Men } & \multicolumn{2}{|r|}{ Women } & \multicolumn{2}{|r|}{ Men } & \multicolumn{2}{|r|}{ Women } \\
\hline & Cases & HR $(95 \% \mathrm{CI})$ & Cases & HR $(95 \% \mathrm{CI})$ & Cases & HR $(95 \% \mathrm{CI})$ & Cases & $\mathrm{HR}(95 \% \mathrm{CI})$ & Cases & HR $(95 \% \mathrm{CI})$ & Cases & HR $(95 \% \mathrm{CI})$ \\
\hline $\begin{array}{l}\text { Gestational age } \\
\text { Early preterm }(<35 \\
\text { weeks })\end{array}$ & 19 & $1.11(0.71-1.75)$ & 24 & $1.54(1.02-2.31)$ & 8 & $1.95(0.96-3.96)$ & 5 & $1.36(0.56-3.31)$ & 11 & $0.98(0.54-1.79)$ & 20 & $1.98(1.27-3.10)$ \\
\hline Preterm (35-36 weeks) & 51 & $1.06(0.80-1.41)$ & 50 & $1.37(1.03-1.83)$ & 13 & $1.05(0.60-1.83)$ & 13 & $1.52(0.86-2.67)$ & 30 & $0.91(0.63-1.31)$ & 30 & $1.24(0.86-1.80)$ \\
\hline Term (37-41 weeks) & 819 & 1 & 706 & 1 & 209 & 1 & 163 & 1 & 554 & 1 & 460 & 1 \\
\hline Post-term ( $\geq 42$ weeks $)$ & 114 & $0.97(0.80-1.18)$ & 101 & $0.96(0.78-1.18)$ & 43 & $1.45(1.04-2.01)$ & 20 & $0.82(0.51-1.30)$ & 79 & $1.02(0.81-1.29)$ & 62 & $0.91(0.69-1.18)$ \\
\hline p-value (heterogeneity) & & 0.92 & & 0.03 & & 0.05 & & 0.32 & & 0.96 & & 0.01 \\
\hline p-value (linear) & & 0.50 & & 0.01 & & 0.59 & & 0.09 & & 0.68 & & 0.005 \\
\hline \multicolumn{13}{|l|}{$\begin{array}{l}\text { Birthweight-for- } \\
\text { gestational-age (quartiles) }\end{array}$} \\
\hline Lowest & 255 & 1 & 192 & 1 & 66 & 1 & 49 & 1 & 172 & 1 & 137 & 1 \\
\hline Second & 267 & $0.95(0.80-1.13)$ & 216 & $0.92(0.76-1.12)$ & 73 & $1.01(0.72-1.41)$ & 52 & $0.88(0.60-1.30)$ & 172 & $0.90(0.73-1.12)$ & 155 & $0.92(0.73-1.16)$ \\
\hline Third & 239 & $0.81(0.68-0.96)$ & 243 & $1.07(0.89-1.30)$ & 63 & $0.83(0.59-1.17)$ & 53 & $0.91(0.62-1.35)$ & 155 & $0.77(0.62-0.96)$ & 141 & $0.87(0.69-1.10)$ \\
\hline Highest & 242 & $0.83(0.69-0.99)$ & 230 & $0.95(0.78-1.15)$ & 71 & $0.94(0.67-1.32)$ & 47 & $0.77(0.51-1.14)$ & 165 & $0.83(0.67-1.02)$ & 139 & $0.79(0.63-1.00)$ \\
\hline p-value (heterogeneity) & & 0.04 & & 0.39 & & 0.66 & & 0.63 & & 0.10 & & 0.26 \\
\hline p-value (linear) & & 0.009 & & 1.00 & & 0.50 & & 0.24 & & 0.04 & & 0.047 \\
\hline \multicolumn{13}{|l|}{$\begin{array}{l}\text { Birth-length-for- } \\
\text { gestational-age (quartiles) }\end{array}$} \\
\hline Lowest & 244 & 1 & 220 & 1 & 63 & 1 & 56 & 1 & 157 & 1 & 155 & 1 \\
\hline Second & 253 & $0.90(0.75-1.07)$ & 193 & $0.87(0.71-1.05)$ & 73 & $1.01(0.72-1.42)$ & 50 & $0.90(0.62-1.32)$ & 181 & $1.00(0.81-1.24)$ & 127 & $0.82(0.65-1.03)$ \\
\hline Third & 241 & $0.91(0.76-1.09)$ & 261 & $0.95(0.79-1.14)$ & 69 & $1.01(0.72-1.43)$ & 47 & $0.68(0.46-1.01)$ & 159 & $0.91(0.73-1.14)$ & 170 & $0.87(0.70-1.08)$ \\
\hline Highest & 265 & $0.87(0.73-1.04)$ & 207 & $0.90(0.74-1.09)$ & 68 & $0.88(0.62-1.24)$ & 48 & $0.84(0.57-1.24)$ & 167 & $0.82(0.66-1.03)$ & 120 & $0.72(0.56-0.91)$ \\
\hline p-value (heterogeneity) & & 0.44 & & 0.47 & & 0.79 & & 0.27 & & 0.25 & & 0.05 \\
\hline p-value (linear) & & 0.16 & & 0.48 & & 0.46 & & 0.19 & & 0.06 & & 0.02 \\
\hline \multicolumn{13}{|l|}{$\begin{array}{l}\text { Head-circumference-for- } \\
\text { gestational-age (quartiles) }\end{array}$} \\
\hline Lowest & 235 & 1 & 204 & 1 & 54 & 1 & 53 & 1 & 156 & 1 & 145 & 1 \\
\hline Second & 323 & $1.01(0.86-1.20)$ & 199 & $1.18(0.97-1.43)$ & 89 & $1.21(0.87-1.70)$ & 41 & $0.93(0.62-1.39)$ & 202 & $0.94(0.76-1.16)$ & 137 & $1.11(0.88-1.41)$ \\
\hline Third & 201 & $0.89(0.73-1.07)$ & 256 & $1.06(0.89-1.28)$ & 55 & $1.06(0.73-1.55)$ & 62 & $0.99(0.68-1.42)$ & 135 & $0.90(0.71-1.13)$ & 162 & $0.93(0.74-1.16)$ \\
\hline Highest & 244 & $0.87(0.72-1.04)$ & 222 & $1.01(0.83-1.22)$ & 75 & $1.17(0.83-1.67)$ & 45 & $0.79(0.53-1.18)$ & 171 & $0.89(0.72-1.11)$ & 128 & $0.79(0.62-1.00)$ \\
\hline p-value (heterogeneity) & & 0.17 & & 0.32 & & 0.67 & & 0.63 & & 0.74 & & 0.04 \\
\hline p-value (linear) & & 0.045 & & 0.79 & & 0.59 & & 0.33 & & 0.29 & & 0.02 \\
\hline \multicolumn{13}{|l|}{ Placental weight (g) } \\
\hline$\leq 550$ & 254 & 1 & 249 & 1 & 60 & 1 & 35 & 1 & 178 & 1 & 160 & 1 \\
\hline $551-650$ & 289 & $0.86(0.72-1.01)$ & 243 & $0.74(0.62-0.88)$ & 87 & $1.11(0.80-1.54)$ & 66 & $1.47(0.98-2.22)$ & 182 & $0.77(0.62-0.94)$ & 157 & $0.76(0.61-0.95)$ \\
\hline $651-750$ & 237 & $0.76(0.64-0.91)$ & 218 & $0.85(0.71-1.02)$ & 68 & $0.94(0.67-1.33)$ & 50 & $1.38(0.90-2.13)$ & 151 & $0.70(0.56-0.87)$ & 141 & $0.88(0.70-1.10)$ \\
\hline
\end{tabular}






HR adjusted for birth cohort with age defining the time scale. *Social mobility during childhood analyses $n=7,985$ (men $n=4,218$; women $n=3,767)$. 


\section{$\underline{\text { Discussion }}$}

In our cohort, gestational age was associated with incident stroke, but to varying degrees. Women born preterm ( $<37$ weeks) had increased risk of TS, and women born early preterm ( $<35$ weeks) had increased risk of OS, compared with women born at term. Gestational age was not associated with HS in women. However, men born post-term had increased risk of HS compared with men born at term.

Social class at birth was associated with stroke in later life only among women; women belonging to lower social classes had an increased risk of HS, whilst women from higher non-manual social class had lower risk of OS compared to all other social groups. Moreover, women who belonged to families who were either upwardly or downwardly mobile had increased risk of TS compared to women whose families were always advantaged.

A strength of our study was using UBCoS Multigen data. This large, well-established historical longitudinal cohort with great completeness of follow-up allowed us to observe individuals across their life course.[18] Our main study population only included individuals with complete data; from our possible sample (see Methods) our study population had low attrition $(8.5 \%)$. However only $74 \%$ of the sample had data on family social class at age 10; therefore for the analyses on social mobility during childhood, there appears to be a selection bias towards those born between 1915 and 1924 and from a skilled manual family social class at birth. Nonetheless, we do not believe this impacted our results in any meaningful way.

While our primary focus was the relationship between gestational age and incident strokes, we also present other birth outcomes for completeness, and this led to many outcomes (as seen in Table 2). Consequently some findings may be due to chance. However, we believe there is good justification to distinguish between different types of strokes and to explore potential gender differences in our analyses. Nevertheless, replication of this study would be valuable.

Moreover, data for incident stroke may be incomplete as the coverage of the National Patient Register was not completed for all parts of Sweden until the 1980s; however, our study subjects were relatively young during the start of follow-up and therefore, may be less affected by this issue.

A limitation of conducting a longitudinal analysis of stroke is that both the availability of diagnostic tools and the ICD codes have changed during our follow-up period; however, our coding is based on relatively larger groups of diagnoses and is consistent with other longitudinal studies which have used stroke subtypes. [10,13]

Furthermore, our construct of social mobility during childhood, based on father's occupation or mother's if she was single, does not capture single motherhood per se but rather transitions in family social class during childhood. Finally, we were unable to assess the risk of stroke among individuals whose family social class was "unemployed" 
as employment status was not captured in the socioeconomic data available to us nor were we able to explore mechanisms linking birth characteristics and later stroke as we did not have access to variables such as smoking, dietary and physical activity habits.

To date, there has been limited evidence of an association between gestational age and stroke in later life, but our findings suggest that an association does exist. Our study supports previous research also conducted in Sweden which showed a link between gestational age and stroke mortality,[9] and another where women who were born $<36$ weeks gestation had double the risk of OS compared to women born 40-41 weeks gestation.[10] Another Swedish study using total population data found that those born $<32$ weeks gestation had nearly double the risk of cerebrovascular disease in young adulthood, but no such risk was observed in those born 32-36 weeks.[11] Although a recent study[12] from the Helsinki Birth Cohort Study found that there was no increased risk of thrombotic, haemorrhagic or all strokes in those born preterm, women born $<34$ weeks had a higher rate of coronary heart disease. Coronary heart disease and TS have similar aetiology with a common mechanism of atherosclerosis, [22] thus it is feasible that if early preterm birth is associated with coronary heart disease, it could also be linked with TS. Moreover, very preterm birth is associated with structural brain alterations in early adulthood, whereby volumetric differences in grey matter and white matter are linearly associated with gestational length.[23] It is possible that these persisting anatomical differences lead to an increased risk of stroke in individuals born preterm in our cohort.

Previous studies have shown that low birthweight $[13,14]$ and low birthweight-forgestational-age[9] are associated with stroke in adulthood. However, when these studies split stroke by subtypes, birthweight was not associated with either TS or HS,[13] nor was birthweight-for-gestational-age associated with TS.9 In comparison, we found that birthweight-for-gestational-age was negatively associated with TS in men only, with no association found with HS. These findings may be reflective of the differences in pathophysiology by stroke subtypes.

The foetal origins hypothesis suggests that malnutrition during critical periods of foetal development may permanently affect physiology, leading to an increased risk of CVD in adulthood.[24] Consistent with this hypothesis we noted that low placental weight was associated with TS in both genders and with OS in men only. Furthermore, placental weight was inversely associated with ischaemic (i.e. coronary) heart disease among individuals from UBCoS Multigen Study.[20] Again, this provides more evidence of a common mechanism for the effect of birth characteristics on TS and ischaemic heart disease.

The premise that individuals with persisting social disadvantage during their childhood will have worse health in adulthood than those who have been advantaged was not observed in our study; however, women who were upwardly or downwardly mobile did have an increased risk of TS. Tiikkaja et al[25] also noted similar associations between stroke mortality and intergenerational class mobility among Swedish women, but they did find that women who were always disadvantaged had an increased risk of stroke 
mortality. Our findings suggest that being socially mobile during childhood can impact one's health in adulthood. This may be due to the stress associated with moving between social groups, where individuals need to adjust to their new social environment.[26] Additionally, unfavourable birth outcomes such as preterm birth and low birthweight are more common among those from social disadvantaged groups.[27] Therefore we could speculate that preterm birth would be associated with stroke as well.

To conclude, our results suggest that birth characteristics are associated with stroke later in life, particularly among women. Women who were born preterm were at increased risk of TS and OS in adulthood, whereas men who were born post-term had increased risk of HS. Social characteristics at birth were only linked to risk of stroke for women and the reasons for this should be further investigated. While globally Sweden has one of the lowest rates of preterm birth affecting around 6\% of births,[28] cerebrovascular disease was the second leading cause of years of life lost due to premature mortality in 2013.[29] Therefore, identifying modifiable risk factors to aid in the prevention of stroke remains a health priority. We believe this study reinforces the importance of healthy birth outcomes and may assist in clarifying the life course aetiology of stroke.

\section{Acknowledgements}

This analysis was supported by grants from the Swedish Research Council (Project No. 2013-5104, 2013-5474) and the Swedish Research Council for Health, Working Life and Welfare (Project No. 2013-1084). I.K. was funded by the Swedish Research Council for Health, Working Life and Welfare (Project No. 2006-1518).

\section{Conflict of interest}

None declared.

\section{$\underline{\text { References }}$}

1. Eriksson JG, Forsen T, Tuomilehto J, Osmond C, Barker DJ. Early growth and coronary heart disease in later life: longitudinal study. BMJ. 2001;322(7292):949-53.

2. Leon DA, Lithell HO, Vagero D, Koupilova I, Mohsen R, Berglund L, et al. Reduced fetal growth rate and increased risk of death from ischaemic heart disease: cohort study of 15000 Swedish men and women born 1915-29. BMJ. 1998;317(7153):241-5.

3. Lawlor DA, Ronalds G, Clark H, Smith GD, Leon DA. Birth weight is inversely associated with incident coronary heart disease and stroke among individuals born in the 1950s: findings from the Aberdeen Children of the 1950s prospective cohort study. Circulation. 2005;112(10):1414-8.

4. Risnes KR, Vatten LJ, Baker JL, Jameson K, Sovio U, Kajantie E, et al. Birthweight and mortality in adulthood: a systematic review and meta-analysis. Int $\mathbf{J}$ Epidemiol. 2011;40(3):647-61. 
5. de Jong F, Monuteaux MC, van Elburg RM, Gillman MW, Belfort MB. Systematic review and meta-analysis of preterm birth and later systolic blood pressure. Hypertension. 2012;59(2):226-34.

6. Lawlor DA, Davey Smith G, Clark H, Leon DA. The associations of birthweight, gestational age and childhood BMI with type 2 diabetes: findings from the Aberdeen Children of the 1950s cohort. Diabetologia. 2006;49(11):2614-7.

7. Kajantie E, Osmond C, Barker DJ, Eriksson JG. Preterm birth--a risk factor for type 2 diabetes? The Helsinki birth cohort study. Diabetes care. 2010;33(12):2623-5.

8. Mathai S, Derraik JG, Cutfield WS, Dalziel SR, Harding JE, Biggs J, et al. Increased adiposity in adults born preterm and their children. PloS One. 2013;8(11):e81840.

9. Koupil I, Leon DA, Lithell HO. Length of gestation is associated with mortality from cerebrovascular disease. J Epidemiol Community Health. 2005;59(6):473-4.

10. Heshmati A, Chaparro MP, Koupil I. Maternal pelvic size, fetal growth and risk of stroke in adult offspring in a large Swedish cohort. J Dev Orig Health Dis. 2016;7(1):108-13.

11. Ueda P, Cnattingius S, Stephansson O, Ingelsson E, Ludvigsson JF, Bonamy AK. Cerebrovascular and ischemic heart disease in young adults born preterm: a populationbased Swedish cohort study. Eur J Epidemiol. 2014;29(4):253-60.

12. Kajantie E, Osmond C, Eriksson JG. Coronary Heart Disease and Stroke in Adults Born Preterm - The Helsinki Birth Cohort Study. Paediatr Perinat Epidemiol. 2015;29(6):515-9.

13. Osmond C, Kajantie E, Forsen TJ, Eriksson JG, Barker DJ. Infant growth and stroke in adult life: the Helsinki birth cohort study. Stroke. 2007;38(2):264-70.

14. Eriksson JG, Forsen T, Tuomilehto J, Osmond C, Barker DJ. Early growth, adult income, and risk of stroke. Stroke. 2000;31(4):869-74.

15. Hypponen E, Leon DA, Kenward MG, Lithell H. Prenatal growth and risk of occlusive and haemorrhagic stroke in Swedish men and women born 1915-29: historical cohort study. BMJ. 2001;323(7320):1033-4.

16. Galobardes B, Smith GD, Lynch JW. Systematic review of the influence of childhood socioeconomic circumstances on risk for cardiovascular disease in adulthood. Ann Epidemiol. 2006;16(2):91-104.

17. The American Heart Association. Types of Stroke. USA: The American Heart Association http://www.strokeassociation.org/STROKEORG/AboutStroke/TypesofStroke/Types-ofStroke_UCM_308531_SubHomePage.jsp. (2016, accessed 04 April 2016).

18. Koupil I. The Uppsala studies on developmental origins of health and disease. J Intern Med. 2007;261(5):426-36.

19. Koupil I, Goodman A. Health Equity: A life course approach. Public Service Review: European Union. 2011;11:382-3.

20. Heshmati A, Koupil I. Placental weight and foetal growth rate as predictors of ischaemic heart disease in a Swedish cohort. J Dev Orig Health Dis. 2014;5(3):164-70.

21. Ludvigsson JF, Andersson E, Ekbom A, Feychting M, Kim JL, Reuterwall C, et al. External review and validation of the Swedish national inpatient register. BMC Public Health. 2011;11:450. 
22. Soler EP, Ruiz VC. Epidemiology and risk factors of cerebral ischemia and ischemic heart diseases: similarities and differences. Curr Cardiol Rev. 2010;6(3):138-49. 23. Nosarti C, Nam KW, Walshe M, Murray RM, Cuddy M, Rifkin L, et al. Preterm birth and structural brain alterations in early adulthood. NeuroImage Clinical. 2014;6:180-91.

24. Barker DJ. Fetal origins of coronary heart disease. BMJ. 1995;311(6998):171-4.

25. Tiikkaja S, Hemstrom $\mathrm{O}$, Vagero $\mathrm{D}$. Intergenerational class mobility and cardiovascular mortality among Swedish women: a population-based register study. Soc Sci Med. 2009;68(4):733-9.

26. Lundberg O. Childhood Living Conditions, Health Status, and Social Mobility: A Contribution to the Health Selection Debate. Eur Sociol Rev. 1991;7(2):149-62.

27. Blumenshine P, Egerter S, Barclay CJ, Cubbin C, Braveman PA. Socioeconomic disparities in adverse birth outcomes: a systematic review. Am J Prev Med. 2010;39(3):26372.

28. March of dimes, The Partnership for Maternal, Newborn \& Child Health, Save the Children, World Health Organisation. Born too Soon: The Global Action Report on Preterm Birth. Geneva: WHO; 2012.

29. Institute for Health Metric and Evaluation. Sweden. USA: University of Washington http://www.healthdata.org/sweden. (2016, accesssed 29 April 2016).

\section{Supplementary Material}

Table S1. Association of social class at birth $(n=10,593)$ with gestational age among study subjects born in Uppsala between 1915-1929.

\begin{tabular}{|c|c|c|c|c|}
\hline & \multicolumn{4}{|c|}{$\mathrm{N}$ (percentage) } \\
\hline & $\begin{array}{c}\text { Early preterm } \\
\text { (<35 weeks) }\end{array}$ & $\begin{array}{c}\text { Preterm }(35-36 \\
\text { weeks })\end{array}$ & $\begin{array}{c}\text { Term }(37-41 \\
\text { weeks })\end{array}$ & $\begin{array}{c}\text { Post-term }(\geq 42 \\
\text { weeks })\end{array}$ \\
\hline \multicolumn{5}{|l|}{ Social class at birth } \\
\hline Higher non-manual§ & $6(0.6)$ & $34(3,6)$ & $804(84,2)$ & $111(11.6)$ \\
\hline $\begin{array}{l}\text { Entrepreneurs and } \\
\text { farmers }\end{array}$ & $37(1.8)$ & $77(3,8)$ & $1,673(82,4)$ & $244(12,0)$ \\
\hline Lower non-manual & $10(1.3)$ & $45(5,9)$ & $621(81,2)$ & $89(11,6)$ \\
\hline Skilled manual & $26(1.6)$ & $83(5,2)$ & $1,281(80,3)$ & $206(12,9)$ \\
\hline Unskilled manual & $112(2.1)$ & $272(5,2)$ & $4,216(80,4)$ & $646(12,3)$ \\
\hline p-value $\S$ & \multicolumn{4}{|c|}{0.01} \\
\hline
\end{tabular}


Table S2. Rates per 100,000 person-years of thrombotic, haemorrhagic and other stroke from 1 January 1964 to 31 December 2008 by early life characteristics; stratified by gender (men n=5,532; women $n=5,061)$.

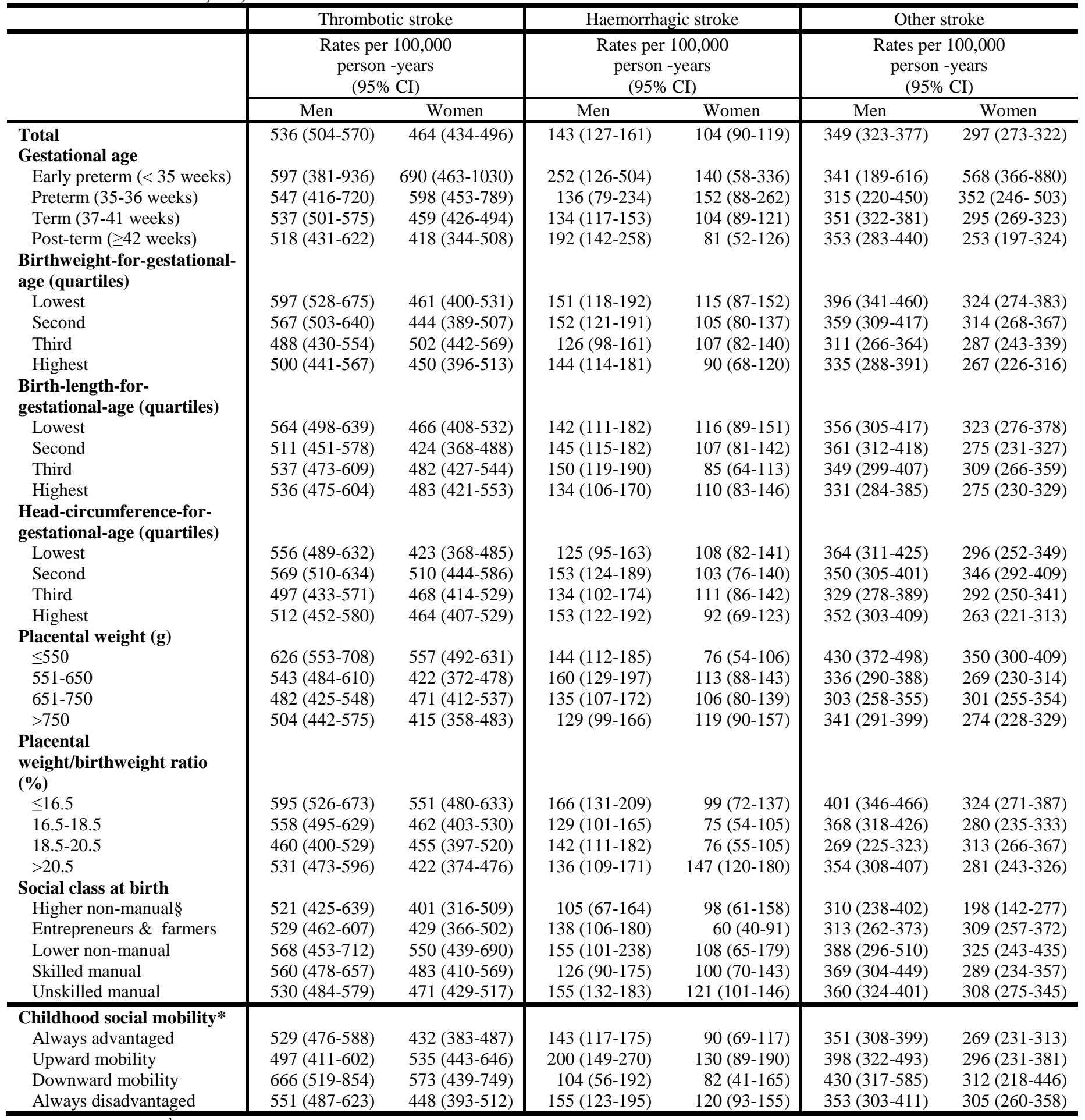

${ }^{\mathrm{a}}$ T-test. ${ }^{\mathrm{b}}$ Pearson $\chi 2$ test

$\S$ Includes intermediate non-manual social class

$*_{n}=7,985$ (men $n=4,218$; women $n=3,767$ ) 
Early life and stroke 